\title{
Concepção de Objetos Digitais de Aprendizagem para Combinatória nos Anos Iniciais
}

\author{
Elisa Friedrich Martins - Programa de Pós-Graduação em Informática na Educação \\ UFRGS-titamat@yahoo.com.br \\ Marcus Vinicius de Azevedo Basso - Programa de Pós-Graduação em Informática na \\ Educação UFRGS- mbasso@ufrgs.br
}

Resumo: O presente artigo apresenta o desenvolvimento de um Objeto Digital de Aprendizagem envolvendo Análise Combinatória voltado para alunos dos anos iniciais do Ensino Fundamental. O planejamento do material digital, suas características e objetivos estão descritos e atendem aos requisitos apontados pela literatura. A concepção está fundamentada na teoria de Jean Piaget sobre a construção do conhecimento. Uma prospecção por material similar nos permitiu concluir não existir Objetos Digitais de Aprendizagem sobre essa temática para a faixa etária considerada, apontando para a necessidade de seu desenvolvimento e na perspectiva de contribuir para a formação Matemática dos alunos dos anos iniciais.

Palavras-chave: Análise Combinatória, Anos iniciais, Objetos de Aprendizagem, Matemática.

\section{Conception of Digital Materials for Combinatorial in the Primary School}

Abstract: The present article presents the development of a Digital Object of Learning involving Combinatorial Analysis aimed at students of the Elementary School. The planning of the material, its characteristics and objectives are described and meet the requirements pointed out in the literature. Also discussed is the theoretical basis on Jean Piaget's knowledge construction used in the object design process. A survey of similar resources allowed us to conclude that there were no Digital Learning Objects on this theme for the age group considered, pointing out the need for its development and the perspective of contributing to the mathematical formation of the students of the Primary School.

Keywords: Combinatorial, Primary School, Learning Objects, Mathematics

\section{Introdução}

Há alguns anos, os alunos dirigiam-se para a biblioteca para realizar trabalhos de pesquisa propostos pelos professores. Hoje, digitam o assunto ou pergunta num site de busca e concluem a tarefa dentro do carro, enquanto almoçam ou mesmo no horário da aula a partir de seus smartphones conectados à rede mundial de computadores: a internet. Mas não foi só a maneira de pesquisar dos alunos que mudou; o modo de viver e pensar das crianças de hoje não é o mesmo que das crianças do século passado.

Estamos mergulhados na Cultura Digital (Brasil, 2010). As comunicações são instantâneas e mediadas por dispositivos eletrônicos, não importando a distância que separa duas pessoas: alguns metros, um bairro, uma cidade ou mesmo um oceano. Tudo é passível de ser fotografado e compartilhado com aqueles que parecem se interessar: o que eu como, como me visto, os escândalos políticos, os acontecimentos mundiais, os fatos esportivos. As pessoas, de modo geral, independente do ano de seu nascimento, 
andam com seus smartphones lendo, escrevendo, fotografando, curtindo, compartilhando, comentando, perguntando e acessando uma grande quantidade de informações. Quando chegam na escola, alunos e professores voltam ao mundo onde lápis e papel são as ferramentas mais importantes. A comunicação, as curtidas, comentários e compartilhamento de informações são agora mediadas por um adulto: o professor.

Para a escola fazer parte da Cultura Digital é preciso que mudanças aconteçam. Mudanças na organização do currículo, na organização dos espaços da escola, na infraestrutura necessária para que toda a escola esteja conectada com o resto do mundo (não é possível estar presente na Cultura Digital sem internet wi-fi, por exemplo) e também no material utilizado em sala de aula. A identificação da necessidade de mudanças faz pensar e incentiva a busca por respostas e soluções. Essa busca vem sendo feita por inúmeros pesquisadores e gerando publicações em âmbito nacional e internacional [Kaput, Hegedus e Lesh, 2007; Coll e Monereo, 2010; Goméz, 2015]. As mudanças apontadas remetem transformações em diferentes âmbitos: gestão, estrutura, política, currículo, formação e atuação docente. A formação de professores, por exemplo, é um campo com expressiva produção científica e pesquisas em andamento, sendo uma linha de pesquisa de programas de mestrado e doutorado oferecidos no Brasil [UNISINOS, UFSC, UECE, PUCSP]. As estruturas das escolas são discutidas no contexto das políticas públicas e dos investimentos em educação. O presente texto discute o material da Escola da Cultura Digital, este não pode ser impresso e fotocopiado, muito menos passado no quadro-negro para ser copiado para os cadernos. O material da Cultura Digital é digital. Mas o que caracteriza esse digital? São sites com aplicativos, animações, jogos, simulações, vídeos, gráficos e infográficos. Um material que permita que cada aluno explore o conceito abordado à sua maneira: com textos e indicações complementares para os mais interessados, explicações simplificadas ou mesmo superficiais para os que estão com dificuldades. Os Objetos Digitais de Aprendizagem (ODA) são alternativas que se encaixam com essa escola da Cultura Digital.

Analisando publicações nacionais acerca do currículo do Ensino Fundamental se evidencia a presença de assuntos relativos à Análise Combinatória desde os primeiros anos de escolarização. Assim, esse texto apresenta uma proposta de desenvolvimento de ODA que trabalhe com Análise Combinatória voltada para os Anos Iniciais do Ensino Fundamental.

A seção 2 deste artigo traz o desenho da pesquisa da qual o ODA é parte imprescindível. A seção 3 traz a decisão pelo recurso digital ODA e a seção 4 a justificativa da escolha do tema análise combinatória. A descrição detalhada do ODA a ser desenvolvido constitui a seção 5 . As considerações finais e a continuidade do trabalho aparecem na seção 6 .

\section{Desenho da pesquisa}

O artigo compreende uma das etapas de uma pesquisa de doutoramento do Programa de Pós-Graduação em Informática na Educação (PPGIE) da UFRGS. A pesquisa iniciou com uma busca, em repositórios de materiais digitais por recursos que contemplassem Combinatória com foco nos Anos Iniciais do Ensino Fundamental. A partir de palavraschave se buscou materiais disponíveis em repositórios ${ }^{1}$ como: a) BIOE: Banco Internacional de Objetos Educacionais, b) RIVED: Rede Internacional Virtual de

1 Os endereços eletrônicos de cada repositório constam nas referências. 
Educação, c) Educapes, d) Portal do Professor, e) Casa das Ciências, f)Wisc-Online. As palavras-chave e o tipo de busca variaram de acordo com a ferramenta de busca disponível em cada repositório. Ora a partir de palavras como "Combinatória”, "Análise Combinatória", ora com a palavra "Matemática" ou seção destinada a essa área de conhecimento. Além de materiais no formato de texto ou hipertexto (distantes do que se buscava) foram localizados materiais voltados para o Ensino Médio, apoiavam as soluções em aplicações de fórmulas, e objetos com questões de múltipla escolha envolvendo o tema. Na prospecção de materiais não foram localizados recursos que se adequassem ao escopo da pesquisa. Assim, percebendo a carência de materiais que se encaixassem nos critérios estabelecidos e a pesquisa se encaminhou para a concepção desses materiais.

Para o desenvolvimento de um ODA que abordasse problemas de Análise Combinatória para ser explorado nos anos inicias do Ensino Fundamental, algumas questões iniciais surgiram: a) Por que Objetos de Aprendizagem? b) Por que Análise Combinatória? Depois de respondidas estas questões, se faz necessário pensar a interface, os objetivos e as possibilidades de interação que o ODA permitirá. Para tais definições a teoria de Jean Piaget sobre a construção do conhecimento oferece suporte teórico. A maneira de aprender das crianças, usuárias do ODA, é levada em consideração na hora de planejar um material com a qual vão interagir. Com isso, é possível descrever e desenvolver o ODA.

\section{Por que Objetos de Aprendizagem?}

Como referido anteriormente, a Cultura Digital exige um material didático-pedagógico que faça uso das potencialidades das tecnologias disponíveis. Essa necessidade fez com que as buscas por soluções e estratégias que possam ser implementadas nesse sentido ganhassem espaço nas universidades. Os programas voltados para uso de tecnologias crescem em número e em membros, aumentando a produção científica sobre o tema. Há incentivo de instituições governamentais e privadas para a produção de material digital, porém, como afirma Tarouco et al. (2014), a quantidade de conteúdos educacionais digitais ainda é muito inferior ao que se considera necessário.

Na mesma obra, Tarouco et al. (2014) colocam que

o que se constata ao procurar um conteúdo educacional digital é que não é fácil encontrar material apropriado para apoiar todas as atividades de ensino e aprendizagem específicas que um professor tenha." (Tarouco et al., 2014, p. 9).

A busca por ODA que tratem da Matemática dos Anos Iniciais traz uma diversidade de materiais tratando das quatro operações, alguns recursos explorando questões de Geometria e também envolvendo frações. Apesar de haver material adequado para a etapa escolar em questão, ainda está longe de ser suficiente para todo o currículo.

A Base Nacional Comum Curricular (BNCC) não trata de ODA, mas aponta para o uso de tecnologias nas aulas de Matemática. Indica como uma das competências específicas de Matemática para o Ensino Fundamental:

Utilizar processos e ferramentas matemáticas, inclusive tecnologias digitais disponíveis, para modelar e resolver problemas cotidianos, sociais e de outras áreas de conhecimento, validando estratégias e resultados. (Brasil, 2017, p.265)

Os Objetos Digitais de Aprendizagem são um tipo de recurso disponível na web. Suas características o fazem uma alternativa interessante para a sala de aula. O próprio termo não é consensual em sua definição, pois a expressão Objeto de Aprendizagem aparece com diferentes definições na bibliografia. Em alguns casos é tratado como Objeto 
Digital de Aprendizagem (ODA) ou Objeto Virtual de Aprendizagem (OVA), noutros contextos aparece como Objetos Digitais e, ainda, como Objetos de Aprendizagem (OA). Em função dos objetivos pensados para o material proposto, trataremos Objetos de Aprendizagem e usaremos a definição de Wiley (2000): “(...) qualquer objeto digital que pode ser reusado para apoiar a aprendizagem." Apesar da definição escolhida usaremos o termo Objeto Digital de Aprendizagem (ODA) para evidenciar que se trata de um recurso relativo ao uso da tecnologia.

Os ODA são um formato de conteúdo digital: aplicativos que permitem uma interação entre o usuário e o computador. Em sua maioria são passíveis de serem utilizados com ou sem professor. Isto é, podem ser explorados a partir de uma proposta feita pelo professor, mas também podem ser utilizados em casa por usuários de diferentes idades, etapas de escolarização ou objetivos. O ritmo com que cada desafio é enfrentado e solucionado não depende de um grupo (turma), mas do explorador. São fáceis de serem acessados, pois ficam disponíveis na internet, mas nada impede que sejam disponibilizados off-line, podendo ser carregados em um pendrive, por exemplo. Acima de tudo, a linguagem e a interface dos ODA se aproxima dos games e da linguagem usada em outros materiais disponíveis na internet, fazendo parte do contexto de vida das crianças e jovens da atualidade.

Para que um recurso seja considerado um ODA, deve, segundo Mendes, Souza e Caregnato (2004), apresentar as seguintes características: reusabilidade, adaptabilidade, granularidade, acessibilidade, durabilidade, interoperabilidade. A reusabilidade e a adaptabilidade consistem em ser um recurso que possa ser utilizado diversas vezes e em diferentes ambientes de ensino. A granularidade prevê que o recurso seja apresentado em pedaços, facilitando a reusabilidade. A acessibilidade indica que o recurso fique disponível na internet, para ser acessado de qualquer lugar. A durabilidade e a interoperabilidade sugerem que o material possa ser acessado independente das mudanças de tecnologia ou de sistema operacional utilizado pelos usuários. Essas características são importantes no desenvolvimento de novos recursos e, assim, levados em consideração para o desenvolvimento do ODA proposto.

\section{Por que Análise Combinatória?}

Diferentes documentos oficiais nacionais apresentam indicações de que os problemas de Análise Combinatória façam parte do currículo desde o Ensino Fundamental. Os Parâmetros Curriculares Nacionais $(\mathrm{PCN})$ e a BNCC tratam especificamente sobre o currículo da Educação Básica no Brasil. Os dois documentos trazem trechos evidenciando a presença desse tema desde os anos inicias do Ensino Fundamental. O Pacto Nacional pela Alfabetização na Idade Certa (PNAIC) promoveu uma formação em massa dos professores dos primeiros três anos do EF, ciclo de alfabetização. $\mathrm{O}$ material produzido para essa formação contem um caderno intitulado Educação Estatística e traz uma discussão sobre o ensino de Combinatória nos anos iniciais e sugestões de atividades a serem realizadas em sala de aula. Ou seja, esse tema deve se fazer presente nas salas de aula do EF.

Apesar de ser aprofundado no Ensino Médio, este tema deve fazer parte dos currículos de Matemática dos anos iniciais do Ensino Fundamental.

Mas por que razão? Uma vez que no Ensino Médio o trabalho acerca de Análise Combinatória utilize fórmulas para resolver problemas envolvendo combinação, arranjo e permutação; no Ensino Fundamental, o objetivo principal é familiarizar-se com o tipo de problema e elencar estratégias de resolução. Muitas vezes os alunos dos anos iniciais 
do EF não são fluentes na leitura e capazes de interpretar problemas escritos, também não efetuam com fluidez os algoritmos das quatro operações matemáticas elementares; os

ODA são, portanto, uma maneira de transpor esses obstáculos. Também por essas razões os documentos oficiais citados falam em "lidar com situações envolvendo combinatória". A indicação não é de que aprendam a resolver os problemas ou compreender em definitivo as diferenças e semelhanças entre as situações de arranjo, permutação e combinação.

A Tabela 1 traz os trechos dos documentos que abordam especificamente o tema:

Tabela 1: Publicações nacionais apontando o ensino de Análise Combinatória

\begin{tabular}{|c|c|c|}
\hline \multirow[b]{2}{*}{$\mathbf{P C N}$} & $\begin{array}{l}1^{\circ} \text { e } 2^{\circ} \text { ciclos } \\
\left(1^{\circ} \text { ao } 5^{\circ}\right. \\
\text { ano })\end{array}$ & $\begin{array}{l}\text { levar o aluno a lidar com situações-problema que envolvam combinações, } \\
\text { arranjos e permutações e, principalmente, o princípio fundamental da } \\
\text { contagem (Brasil, 1997, p. 57) }\end{array}$ \\
\hline & $\begin{array}{l}3^{\circ} \text { e } 4^{\circ} \text { ciclo } \\
\left(6^{\circ} \text { ao } 9^{\circ}\right. \\
\text { ano })\end{array}$ & $\begin{array}{l}\text { (...) o objetivo é levar o aluno a lidar com situações que envolvam } \\
\text { diferentes tipos de agrupamentos que possibilitem o desenvolvimento do } \\
\text { raciocínio combinatório e a compreensão do princípio multiplicativo para } \\
\text { aplicação no cálculo de probabilidade. (Brasil, 1998, p.52). }\end{array}$ \\
\hline \multirow{2}{*}{ BNCC } & $4^{\circ}$ ano & $\begin{array}{l}\text { Resolver, com o suporte de imagem e/ou material manipulável, problemas } \\
\text { simples de contagem, como a determinação do número de agrupamentos } \\
\text { possíveis ao se combinar cada elemento de uma coleção com todos os } \\
\text { elementos de outra, utilizando estratégias e formas de registro pessoais. } \\
\text { (Brasil, 2017, p. 289). }\end{array}$ \\
\hline & $5^{\circ}$ ano & $\begin{array}{l}\text { Resolver e elaborar problemas simples de contagem envolvendo o } \\
\text { princípio multiplicativo, como a determinação do número de agrupamentos } \\
\text { possíveis ao se combinar cada elemento de uma coleção com todos os } \\
\text { elementos de outra coleção, por meio de diagramas de árvore ou por } \\
\text { tabelas. (Brasil, 2017, p. 293). }\end{array}$ \\
\hline PNAIC & & $\begin{array}{l}\text { O desenvolvimento do raciocínio combinatório é um processo longo. É } \\
\text { necessário, portanto, que durante a escolarização os diferentes tipos de } \\
\text { problemas sejam trabalhados e que haja um aprofundamento contínuo para } \\
\text { que estratégias próprias das crianças, mais informais, sejam } \\
\text { gradativamente transformadas em procedimentos e sistematizados. (Brasil, } \\
2014, \text { p. 50). }\end{array}$ \\
\hline
\end{tabular}

Piaget, no seu livro Da Lógica da Criança à Lógica do Adolescente (1976) afirma que o pensamento combinatório e a construção de listas organizadas seriam atividades do período formal. Ou seja, apenas com cerca de 12 anos é que esses problemas seriam completamente compreendidos e resolvidos. Porém, pesquisas recentes mostram que crianças dos anos inicias já conseguem resolver alguns problemas envolvendo análise combinatória (Pessoa, 2009; Azevedo, 2013; Oliveira, 2014; Silva, 2016). Contudo, dada a importância dos estudos de Piaget e a relevância de suas pesquisas o material a ser desenvolvido não pretende que crianças sejam capazes de solucionar todos os tipos de problemas de análise combinatória. Mas que sejam instigadas a pensar sobre esse tipo de questão e que comecem a construir suas soluções. O fato de não ter estruturas que permitam a resolução por completo e a justificativa do esgotamento de possibilidades, $o$ envolvimento com os problemas e o enfrentamento deste tipo de desafio são válidos e importantes para a formação matemática das crianças.

\section{O Objeto}

Para o desenvolvimento do ODA se utiliza as características necessárias indicadas por 
Mendes et al. (2004), sejam elas: reusabilidade, adaptabilidade (quanto a ambientes de ensino), granularidade, acessibilidade (referente ao local, ou seja, disponível na internet), durabilidade (quanto às mudanças de tecnologia) e interoperabilidade (quanto aos

hardware, browser, sistemas operacionais). Também são levados em conta os aspectos técnicos apontados por Reategui, Boff e Finco (2010). Estes aspectos se dividem entre requisitos e interface, sendo que os requisitos apontados tratam da robustez e da portabilidade. A portabilidade corrobora com os itens interoperabilidade e durabilidade de Mendes et al. (2004) e a robustez avalia a presença ou ausência de erros e o funcionamento em caso de erro. Quanto a interface, se discute o emprego de imagens, a apresentação das informações, condições de orientação e navegação, interatividade, estética e afetividade.

Além disso, Reategui, Boff e Finco (2010) também indicam que os aspectos pedagógicos são importantes na hora de criar um ODA. A formulação das perguntas e o tipo de ação proposto nesse ODA fundamentam-se na teoria da construção do conhecimento de Jean Piaget. Da teoria também surgiram as questões apresentadas a partir das respostas dadas, sejam elas corretas ou incorretas.

Para atender às necessidades apresentadas anteriormente decidiu-se por desenvolver o ODA em hmtl5. A linguagem é atual e permite acesso por diferentes dispositivos, rodando em aplicativos de navegação (GoogleChrome, Edge, Mozzila Firefox, etc.). Para que se encaixe nos requisitos de reuso e possibilidades de adaptação será publicado com uma licença Creative Commons, que permite que o código seja alterado e modificado na construção de outras adaptações, desde que apresentada a autoria inicial.

Como funciona este ODA? O ODA proposto contempla nove problemas envolvendo combinação, arranjo e permutação. Cada problema é apresentado em uma tela diferente, a partir de um menu inicial, e permite a construção da solução fazendo uso de imagens. Tal formato contempla a granularidade apontada por Mendes et al. (2004) e a potencialidade de reuso e de adaptação, permitindo diferentes usos para o material.

$\mathrm{O}$ formato do objeto se assemelha a um jogo. O objetivo é resolver cada problema apresentado e, para encontrar a solução, o usuário pode manipular objetos (que são os elementos apresentados no problema) e construir as possibilidades. Para informar a resposta encontrada o usuário preenche uma caixa de texto, onde deve inserir a resposta numérica. Dependendo da resposta dada o objeto apresenta uma resposta (feedback) que pode ser a mensagem de êxito ou uma indicação de que algo está incorreto. No caso de apresentar uma resposta inferior à resposta correta, a indicação será a de rever e tentar encontrar as possibilidades que faltam. No caso da resposta informada ser maior que a resposta correta, a indicação será a de conferir se não foram contadas mais de uma vez alguma possibilidade. Se errar novamente, a indicação será a de rever o que é necessário para construir uma possibilidade e apresentará alguns exemplos.

Além de apresentar as questões escritas, o ODA contém um ícone que pode ser clicado para que a pergunta seja ouvida em áudio. Esse recurso pretende auxiliar os alunos com pouca fluência na leitura a compreender o problema a ser resolvido.

Os problemas a serem transformados em objetos digitais contemplam situações de combinação, arranjo e permutação. Apresentam uma questão e disponibilizam imagens que podem ser arrastadas de modo que a construção das possibilidades seja construída na tela. 


\begin{tabular}{|l|}
\hline UNIFORME DA COLÔMBIA \\
A bandeira da Colômbia é azul, vermelha e amarela com um brasão. Para os \\
uniformes do time de vôlei a equipe do vestuário tem a disposição camisetas vermelhas, \\
amarelas e azuis. Da mesma forma, os calções disponíveis são lisos, nas cores azul, vermelha \\
ou amarela. Quantos uniformes diferentes (camiseta+calção) podem ser formados com essas \\
opções de camiseta e calção? \\
Questões adicionais: \\
Em quantas dessas opções o uniforme fica de um cor só? \\
Em quantas dessas opções o uniforme não possui nenhuma peça amarela? \\
Em quantas dessas opções o uniforme tem alguma peça azul?
\end{tabular}

Quadro 1. Problema apresentado na forma de ODA. Fonte: Elisa F. Martins

Ao construir a solução e acertar a primeira resposta, as perguntas adicionais serão apresentadas, desafiando o usuário a buscar outras informações no conjunto de possibilidades montado.

O problema apresentado no quadro 1 prevê a construção das nove possibilidades de uniforme para o time da Colômbia:

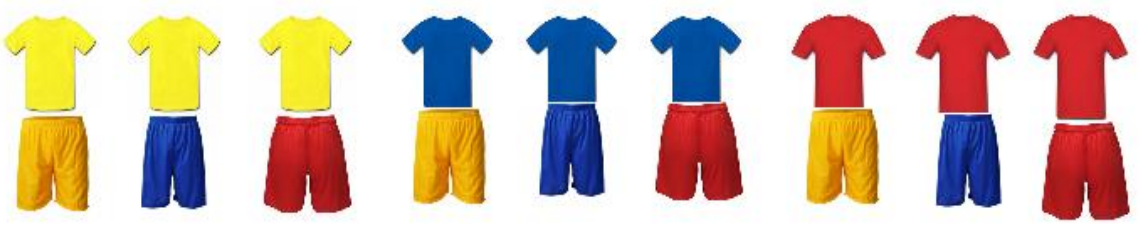

Figura 1. Possivel solução para o problema dos uniformes da Colômbia. Fonte: Elisa F. Martins

No entanto, não é necessário construir as nove opções para responder corretamente à pergunta. É possível montar as três opções com a camiseta amarela e concluir que seriam três uniformes diferentes para cada opção de camiseta e, assim, chegar ao resultado correto que é nove. Para responder às questões adicionais o usuário poderá completar as possibilidades não construídas ou refinar seu raciocínio combinatório e responder a partir de ações mentais. Para a primeira pergunta adicional bastaria pensar que apenas em três possibilidades o uniforme fica de uma cor só: azul, amarelo ou vermelho. Para a segunda questão poderia se retirar as peças amarelas e pensar que seriam duas opções de camiseta (azul e vermelho) e duas opções de bermuda, totalizando quatro possibilidades. A terceira pergunta requer que se analisem as possibilidades com uma ou duas peças azuis. Portanto, os uniformes com camiseta azul (3), os uniformes com calção azul (3). O resultado não é seis, pois o uniforme com camiseta e calção azul aparece nas duas listas e deve ser contabilizado apenas uma vez. Portanto, a resposta da terceira pergunta é cinco. Esse número pode ser verificado com a contagem das opções que se encaixam na solicitação a partir da lista completa construída (figura 1).

Para trabalhar com a situação de arranjo, um dos problemas propostos prevê a construção de possibilidades de organização de um pódio (Quadro 2).

\section{PÓDIO}

Marcelo, Vitor, Rafael e Pedro resolveram apostar uma corrida. Os quatro se esforçaram muito para ser rápidos, mas apenas três deles subiram ao pódio. De quantas maneiras podem se colocar nesse pódio, sendo que o lugar indica se chegou em primeiro, em segundo ou em terceiro lugar?

Questões adicionais:

Em quantas opções Marcelo é o primeiro colocado?

Em quantas organizações de pódio Vitor aparece?

Quadro 2. Exemplo de problema envolvendo arranjo. Fonte: Elisa F. Martins 
Para a construção das possibilidades é permitido colocar "pódios" e posicionar o rosto dos meninos ou os nomes dos mesmos. A sistematização da construção da solução é imprescindível para a correta solução do problema, pois se trata de um número grande de possibilidades (24). Da mesma maneira que o problema anterior, é possível construir apenas uma parte dele e concluir a partir daí. Por exemplo, se construir os pódios em que Marcelo aparece em primeiro (seis possibilidades) é correto concluir que para os outros acontecerá da mesma forma. Como algum deles é o campeão da corrida, o total são vinte e quatro possibilidades de organização do pódio. Para responder às questões adicionais é possível observar a construção da solução completa ou construir novos raciocínios a partir das novas condições impostas.

Assim como nos exemplos apresentados, os demais problemas também envolvem um universo numérico de seis a vinte e quatro. Isso foi pensado para que se possam construir todas as possibilidades na tela do ODA com os ícones (imagens). Também foram escolhidos esses valores para que se possa dar importância e atenção ao pensamento combinatório, não interessando a dimensão dos cálculos a serem efetuados. Inclusive, a proposta do ODA é que não se pense em cálculos, mas em construções de possibilidades e estratégias de construção de listas.

A decisão de permitir a possibilidade de construção da solução na tela foi tomada a partir da teoria de Jean Piaget. Ele diz que

(...) compreender é inventar, ou reconstruir através da reinvenção, e será preciso curvar-se ante tais necessidades se o que se pretende, para o futuro, é moldar indivíduos capazes de produzir ou de criar, e não apenas de repetir. (Piaget, 2007, p. 17).

A partir disso, o desenho do ODA proposto pretende proporcionar a invenção e a reconstrução de soluções. Para que, agindo sobre os elementos do problema, se construa as possibilidades e se busque uma estratégia de construção que permita esgotar as mesmas.

É preciso, então, que as crianças ajam sobre os problemas de Análise Combinatória. Que se envolvam com essas situações e que possam modificar e transformar esse tipo de problema. Durante essas ações, que podem ser modificações ou transformações, o conhecimento acerca do problema vai se construindo e levando o sujeito envolvido à compreensão dos conceitos. Como Piaget coloca em outro livro

$\mathrm{O}$ conhecimento não é uma cópia da realidade. Para conhecer um objeto, para conhecer um acontecimento não é simplesmente olhar e fazer uma cópia mental, ou imagem, do mesmo. Para conhecer um objeto é preciso agir sobre ele. Conhecer é modificar, transformar o objeto, e compreender o processo dessa transformação e, consequentemente, compreender o modo como o objeto é construído. Uma operação é, assim, a essência do conhecimento. É uma ação interiorizada que modifica o objeto do conhecimento." (Piaget,1972, p1).

O ODA em construção está sendo desenvolvido com as implicações teóricas e técnicas tendo a mesma relevância e importância. Sendo assim, as ferramentas técnicas são pensadas e implementadas com base no que a programação permite e também com base no que aponta a teoria cognitiva apresentada pelos autores. Os problemas apresentados nos quadros 1 e 2 já podem ser testados e passam por correções e ajustes de programação. Ainda sofrerão modificações relativas ao design, mas já estão quase prontos para a etapa de validação. 


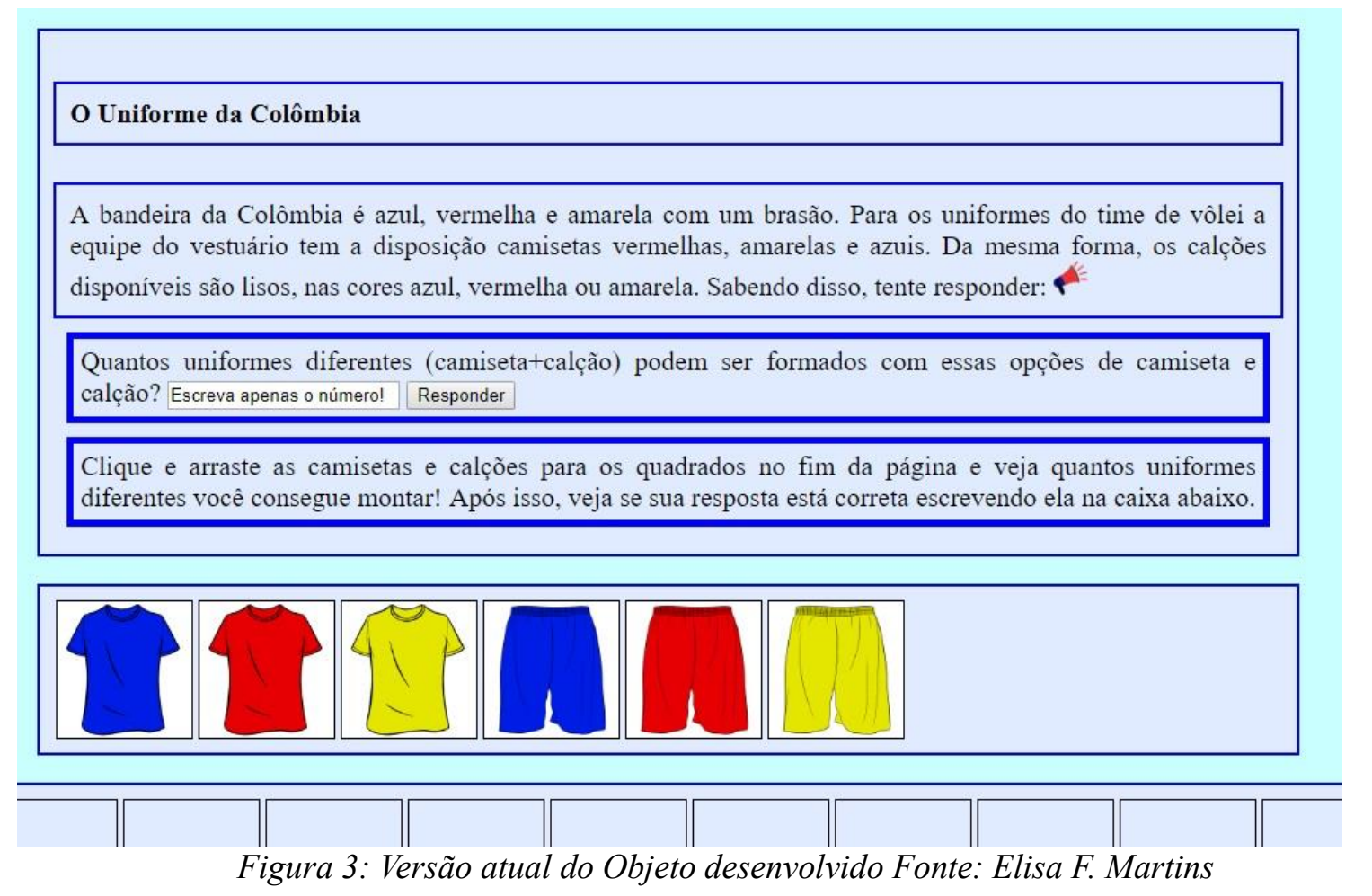

\section{Considerações finais}

A pesquisa desenvolvida até o presente momento permite identificar uma lacuna importante quanto a existência de materiais para trabalhar Análise Combinatória com os alunos dos anos inicias do Ensino Fundamental. Materiais sobre o tema foram encontrados focados nos alunos do Ensino Médio e os materiais para essa etapa de escolarização não abordam esses tipos de problemas. De tal conclusão surge a necessidade de se desenvolver tais Objetos Digitais de Aprendizagem.

O ODA proposto encontra-se numa versão inicial (figura 3) e já disponibiliza algumas das ferramentas apontadas no texto. Ainda faltam ajustes para que possa ser validado e, a partir de uma versão mais consistente - no que se refere às ferramentas disponíveis -, desenvolver os outros sete problemas elaborados.

\section{Referências bibliográficas}

AZEVEDO, J. Alunos de anos iniciais construindo árvores de possibilidades: é melhor no papel ou no computador? Recife, Universidade Federal de Pernambuco, 2013. Dissertação de Mestrado

BIOE: Banco Internacional de Objetos Educacionais. Repositório. Disponível em: <http://objetoseducacionais2.mec.gov.br/> Acesso em: 15 de maio de 2018.

BRASIL, MEC. Parâmetros Curriculares Nacionais. Matemática. $1^{\circ}$ e $^{\circ}$ ciclos. Brasília: Secretaria de Ensino Fundamental, 1997.

Parâmetros Curriculares Nacionais. Matemática. $3^{\circ}$ e $4^{\circ}$ ciclos. Brasília: Secretaria de Ensino Fundamental, 1998.

Caderno Cultura Digital. Série Mais Educação. Brasília: Secretaria de Educação Básica, 2010.

Educação Estatística. Pacto Nacional pela Alfabetização na Idade Certa. 
Brasília: Secretaria de Educação Básica, 2014.

Básica, 2017.

Base Nacional Comum Curricular. Brasília: Secretaria de Educação

BRASIL, MEC. Portal do Professor. Repositório. Disponível em $<$ http://portaldoprofessor.mec.gov.br/> Acessado em: 15 de maio de 2018.

CASA DAS CIÊNCIAS. Repositório. Disponível em:

$<$ https://www.casadasciencias.org/> Acessado em: 15 de maio de 2018.

CAPES. EDUCAPES. Repositório. Disponível em:

$<$ https://educapes.capes.gov.br/> Acessado em: 15 de maio de 2018.

COLL, C.; MONEREO, C. (Orgs.). Psicologia da educação virtual - Aprender e Ensinar com as Tecnologias da Informação e da Comunicação. Porto Alegre: Artmed, 2010.

GOMÉZ, A. I. P. Educação na era digital: a escola educativa. Porto Alegre: Artmed, 2015.

KAPUT, J; HEGEDUS, S.; LESH, R. Technology Becoming Infrastructural in Mathematics Education. In: Foundations for the Future in Mathematics Education. New Jersey: Lawrence Erlbaum Associates, 2007. Capítulo 8, p. 173-191.

MENDES, R. M.; SOUZA, V. I.; CAREGNATO, S. E. A propriedade intelectual na elaboração de objetos de aprendizagem. In: Cinform - Encontro Nacional de Ciência da Informação, 2004, Salvador. Anais, Salvador: UFBA, 2004.

OLIVEIRA, E. G. Raciocínio combinatório na resolução de problemas nos anos iniciais do ensino fundamental: um estudo com professores. São Paulo, Pontifícia Universidade Católica de São Paulo, 2014. Dissertação de Mestrado.

PESSOA, C. A. S. Quem dança com quem: o desenvolvimento do raciocínio combinatório do $2^{\circ}$ ano do Ensino Fundamental ao $3^{\circ}$ ano do Ensino Médio. Recife, Universidade Federal de Pernambuco, 2009. Tese de Doutorado.

PIAGET, J. Para onde vai a educação? 18. Edição. Tradução de Ivette Braga. Rio de Janeiro: José Olympio, 2007 [1972].

PIAGET, J. Development and learning. In: LAVATTELLY, C. S. e STENDLER, F.

Reading in child behavior and development. New York: Hartcourt Brace Janovich, 1972. (Trad.: Paulo Slomp, prof. FACED/UFRGS. Revisão: Fernando Becker, PPGEduUFRGS)

PIAGET, J., INHELDER, B. Da lógica da criança à lógica do adolescente. São Paulo: Editora Pioneira. [1976]

REATEGUI, E., BOFF, E., FINCO, M. D. Proposta de Diretrizes para Avaliação de Objetos de Aprendizagem Considerando Aspectos Pedagógicos e Técnicos. In: Revista Novas Tecnologias na Educação V. 8 Nº 3, dezembro, 2010

RIVED. Rede Internacional Virtual de Educação. Repositório. Disponível em: $<$ http://rived.mec.gov.br/> Acessado em: 15 de maio de 2018.

SILVA, M. C. A combinatória: abordagem em documentos oficiais, em resultados de pesquisas e em livros didáticos do Ensino Fundamental. Recife, Universidade Federal de Pernambuco, 2016. Dissertação de mestrado.

TAROUCO, L., M. R., ÁVILA, B. G., SANTOS, E. F., BEZ, M. R., COSTA, V. (Org.) Objetos de Aprendizagem: teoria e prática. Porto Alegre: Evangraf, 2014.

WILEY, D. A. Learning object design and sequencing theory. Brigham Young University. 2000. Doctoral dissertation.

WISC-ONLINE. Repositório. Disponível em: <https://www.wisc-online.com/> Acessado em: 15 de maio de 2018. 